\title{
Jefferson
}

Thomas Jefferson University

\section{The Rare Case of Streptococcus Pyogenes Pneumonia and Its Sequelae}

\author{
Fern Martin, MD \\ Thomas Jefferson University, fern.martin@jefferson.edu \\ Gloria Francis, MD \\ Thomas Jefferson University, gloria.francis@jefferson.edu
}

Follow this and additional works at: https://jdc.jefferson.edu/tmf

Part of the Medicine and Health Sciences Commons

Let us know how access to this document benefits you

\section{Recommended Citation}

Martin, MD, Fern and Francis, MD, Gloria (2015) "The Rare Case of Streptococcus Pyogenes Pneumonia and Its Sequelae," The Medicine Forum: Vol. 16 , Article 17.

DOI: https://doi.org/10.29046/TMF.016.1.016

Available at: https://jdc.jefferson.edu/tmf/vol16/iss1/17

This Article is brought to you for free and open access by the Jefferson Digital Commons. The Jefferson Digital Commons is a service of Thomas Jefferson University's Center for Teaching and Learning (CTL). The Commons is a showcase for Jefferson books and journals, peer-reviewed scholarly publications, unique historical collections from the University archives, and teaching tools. The Jefferson Digital Commons allows researchers and interested readers anywhere in the world to learn about and keep up to date with Jefferson scholarship. This article has been accepted for inclusion in The Medicine Forum by an authorized administrator of the Jefferson Digital Commons. For more information, please contact: JeffersonDigitalCommons@jefferson.edu. 


\title{
The Rare Case of Streptococcus Pyogenes Pneumonia and Its Sequelae
}

\author{
Fern Martin, MD and Gloria Francis, MD
}

\section{INTRODUCTION}

Group A Streptococcus (GAS) or Streptococcus pyogenes is an aerobic gram-positive coccus that causes a multitude of infections that range in severity. GAS most commonly infects the soft tissues, which results in infections such as cellulitis, erysipelas, necrotizing fasciitis and myositis. These deep soft tissue infections are also the most common source of GAS bacteremia. Other common infections caused by GAS include pharyngitis, rheumatic fever and glomerulonephritis. ${ }^{1}$ The lower respiratory tract is an uncommon site for GAS infection and it is the least common source of GAS bacteremia; however, in adults with GAS pneumonia, the incidence of bacteremia is 80 percent. ${ }^{2}$ Patients with a severe GAS infection can develop streptococcal toxic shock syndrome, which consists of GAS bacteremia in conjunction with shock and organ failure. Here we present a case of severe GAS pneumonia complicated by toxic shock syndrome and purpura fulminans, a rare complication of disseminated GAS infection.

\section{CASE PRESENTATION}

A 57-year-old male with a history of gastric adenocarcinoma status post partial gastrectomy presented with a two-day history of shortness of breath and chest tightness. He denied any associated fevers, cough, sputum production, pharyngitis, diarrhea or dysuria. In the emergency room, he was afebrile (although he had been taking acetaminophenoxycodone tablets every 4 to 6 hours for his chest pain) with a heart rate of $123 \mathrm{bpm}$, blood pressure $78 / 49 \mathrm{mmHg}$, respiratory rate $21-27 \mathrm{bpm}$, and pulse oximetry of $94 \%$ on a non-rebreather. Physical exam revealed right upper lobe rales, as well as egophony and sinus tachycardia. There was no evidence of pharyngeal erythema, exudates, or ulcers. Pertinent lab work on admission included a creatinine of $2.3 \mathrm{mg} / \mathrm{dL}$ and a lactate of $9.0 \mathrm{mmol} / \mathrm{L}$. Computed tomography (CT) of his chest was consistent with pneumonia in the right upper lobe with patchy areas of consolidation in the right middle and lower lobes. The patient received ceftriaxone, azithromycin and five liters of normal saline. He was admitted to the medical intensive care unit (MICU) for severe sepsis secondary to communityacquired pneumonia.

\section{INVESTIGATIONS AND TREATMENT}

After fluid resuscitation and antibiotic initiation, the patient's vital signs improved to a heart rate of $102 \mathrm{bpm}$ and blood pressure of $116 / 72 \mathrm{mmHg}$. On hospital day 2 , the patient had a temperature of $103.1^{\circ} \mathrm{F}$, heart rate 108 bpm, blood pressure $91 / 60 \mathrm{mmHg}$, respiratory rate 35 bpm, and pulse oximetry of $90 \%$ on a non-rebreather. The patient was intubated for acute hypoxic respiratory failure. His rapid influenza test was negative and gram stain from blood cultures revealed gram-positive cocci in chains. The team presumed that the patient had a Streptococcus species pneumonia with subsequent bacteremia. Over the next twelve hours, the patient continued to be hypotensive and a norepinephrine infusion was started. He subsequently developed acute oliguric renal failure, which required hemodialysis. Blood cultures grew Streptococcus pyogenes, but despite appropriate intravenous (IV) antibiotics and vasopressors, the patient remained hypotensive and his lactate rose to $12.2 \mathrm{mmol} / \mathrm{L}$. On hospital day 3, his bilateral dorsalis pedis, posterior tibialis, and left radial pulses were absent. He developed areas of ecchymoses on his lower extremities that evolved into indurated, well-demarcated purple papules with erythematous borders. The patient was diagnosed with purpura fulminans given his vascular thromboses and disseminated intravascular coagulopathy. He was started on clindamycin and given a dose of intravenous immunoglobulin for presumed toxic shock syndrome secondary to GAS bacteremia. His overall status continued to worsen, as he developed ischemic limbs, shock liver and worsening mental status. Vascular surgery was emergently consulted and felt the patient would require amputations of all distal extremities if he were to recover hemodynamically. On hospital day 5, the patient's pupils were minimally responsive and he had temperatures of $107^{\circ} \mathrm{F}$. It was felt the patient had a cerebral event and a CT scan of the head was ordered. He had a witnessed seizure in the radiology department and developed atrial fibrillation that ultimately became asystole. No cardiopulmonary resuscitation (CPR) was initiated as the patient was made do not resuscitate (DNR) by his family. The patient was pronounced dead in the MICU, and his family was notified. 


\section{The Medicine Forum, Vol. 16 [2015], Art. 17}

\section{DISCUSSION}

GAS is an aerobic gram-positive beta-hemolytic coccus that causes an array of diseases in all age groups. In patients over the age of forty, risk factors for developing GAS bacteremia include burns, surgical procedures, trauma, nosocomial transmission, chronic steroid use, cardiac disease, diabetes mellitus, peripheral vascular disease, malignancy and immunosuppression ${ }^{3,4}$. Early recognition of GAS bacteremia is important to improving survival. GAS bacteremia can lead to shock and organ failure, such as renal failure, acute respiratory distress syndrome, hepatic failure and diffuse capillary leak syndrome. ${ }^{1}$ Streptococcal toxic shock syndrome (TSS) can be caused by any streptococcal species, but it is most commonly associated with GAS. ${ }^{5}$ The mortality rate for patients with GAS bacteremia is approximately 35 percent; however once TSS develops, the mortality rate is 79 percent. $^{6}$

In addition to aggressive fluid resuscitation, GAS TSS must also be treated with IV antibiotics. GAS is susceptible to beta-lactam antibiotics, but there is a high failure rate in invasive infections.? Beta-lactams, such as penicillin $G$, inhibit cell wall synthesis, but can be overwhelmed by a large inoculum size. Clindamycin should be added to the antibiotic regimen to suppress toxin production by inhibiting protein synthesis. ${ }^{8}$ Intravenous immune globulin (IVIG) can also be used as an adjunctive therapy. Though data on using IVIG in patients with streptococcal TSS is limited, it is believed that IVIG helps by raising antibody levels in patients with invasive infections. ${ }^{8} \mathrm{~A}$ study conducted by Carapetis et al. examined eighty-four patients with invasive GAS infections. The primary outcome of mortality was compared across patients who received clindamycin as a single adjunct versus patients who received dual adjunct therapy with clindamycin and IVIG. ${ }^{8}$ Patients treated with clindamycin often had more severe disease but lower mortality (15\% versus 39\%). ${ }^{8}$ Patients who received IVIG in addition to clindamycin had an even lower mortality rate, at $7 \% .{ }^{8}$

Our patient presented with common features of GAS TSS, including shock and multi-organ failure, as well as rarer manifestations, such as purpura fulminans and limb ischemia. Purpura fulminans is most commonly seen in children with invasive group B beta-hemolytic streptococcal infections, ${ }^{9}$ but it has also been reported in association with GAS.10 In adults, purpura fulminans is most commonly associated with Neisseria meningitidis, followed by streptococcal species. ${ }^{11}$ In asplenic adults, purpura fulminans is associated with Streptococcus pneumoniae bacteremia. ${ }^{22}$ It can also occur in individuals with inherited or acquired deficiencies in the Protein C or Protein $\mathrm{S}$ anticoagulant pathway. ${ }^{13}$ Purpura fulminans is rarely reported in adults with GAS bacteremia who have functioning spleens. Purpura fulminans is a severe, life-threatening syndrome in which disseminated intravascular coagulation (DIC) leads first to hemorrhagic skin infarcts and progresses to limb ischemia. When purpura fulminans is due to sepsis, the vascular lesions causing the classical skin findings also involve a variety of organs, including the kidneys, lungs, and adrenal glands. The mortality rate associated with purpura fulminans is typically greater than 50 percent.11

The pathogenesis of sepsis-induced purpura fulminans involves bacterial endotoxin mediated disturbances of procoagulant and anticoagulant activities in vascular endothelial cells. Anticoagulant factors become widely consumed, leading to a state of DIC.14 The initial clinical manifestation of purpura fulminans is typically a petechial, purpuric rash. Other clinical features include the classical manifestations of sepsis, such as fevers and hypotension. The characteristic petechial rash typically develops 12-24 hours after onset of infectious symptoms, which in the above patient included shortness of breath and chest tightness. As hemorrhagic skin infarction progresses, the petechiae coalesce to form purpuric ecchymoses. Hemorrhagic bullae can then form and develop into dry gangrene. ${ }^{15}$

Treatment is mainly supportive and also targets the bacterial trigger of purpura fulminans."1 The majority of affected patients require intensive care unit monitoring for aggressive fluid resuscitation, inotropic support, mechanical ventilation, and/or hemodialysis. Surgery can be performed to debride necrotic tissue, but most affected patients eventually require amputations of ischemic limbs. ${ }^{16}$ Various therapies have been proposed to target the coagulation pathway deficiencies associated with purpura fulminans, but none have showed any significant clinical efficacy. ${ }^{11}$ Recombinant activated protein $\mathrm{C}$ has been described as a promising adjunctive therapy in a number of case studies and retrospective studies; however, no randomized controlled trials have been performed to demonstrate its effectiveness. ${ }^{17}$ 
Martin, MD and Francis, MD: The Rare Case of Streptococcus Pyogenes Pneumonia and Its Sequelae

\section{REFERENCES}

1. Stevens DL. Invasive group A streptococcus infections. Clin Infect Dis 1992; $14: 2$

2. Muller MP, Low DE, Green KA, et al. Clinical and epidemiologic features of group a streptococcal pneumonia in Ontario, Canada. Arch Intern Med 2003; 163:467.

3. Kiska DL, Thiede B, Caracciolo J, et al. Invasive group A streptococcal infections in North Carolina: epidemiology, clinical features, and genetic and serotype analysis of causative organisms. J Infect Dis 1997; 176:992.

4. Factor SH, Levine OS, Schwartz B, et al. Invasive group A streptococcal disease: risk factors for adults. Emerg Infect Dis 2003; 9:970.

5. Al-ajmi JA, Hill P, O'Boyle C, Garcia MLB, Malkawi M, George A Saleh F, Lukose B, Ali, BA, Elsheikh M. Group A Streptococcus Toxic Shock Syndrome: An outbreak report and review of the literature. $\mathrm{J}$ Infection and Pub Health. 2012; 5: 388-393.

6. Francis J, Warren RE. Streptococcus pyogenes bacteraemia in Cambridge--a review of 67 episodes. Q J Med 1988; 68:603.

7. Gastanaduy AS, Kaplan EL, Huwe BB, et al. Failure of penicillin to eradicate group A streptococci during an outbreak of pharyngitis. Lancet 1980; 2:498.

8. Carapetis JR, Jacoby P, Carville K, Ang S-JJ, Curtis N, Andrews R. Effectiveness of Clindamycin and Intravenous Immunoglobulin and Risk of Disease in Contacts, in Invasive Group A Stretoccoal Infections. Clin Infect Dis. 2014; 59: 358-365.

9. Daskalaki M, Boeckx WD, DeMey A, et al. Toxic shock syndrome due to group A beta-hemolytic streptococcus presenting with purpura fulminans and limb ischemia in a pediatric patient treated with early microsurgical ateriolysis. J Ped Surg 2013;48: E1-3.

10. Daskalaki M-A, Boeckx WD, DeMey A, Franck, D. Toxic shock syndrome due to group A beta-hemolytic streptococcus presenting with purpura fulminans and limb ischemia in a pediatric patient treated with early microsurgical arteriolysis. J Pediatric Surg. 2013; 48: E1-E3.

11. Carpenter CT, Kaiser AB. Purpura fulminans in pneumococcal sepsis: case report and review. Scand J Infect Dis. 1997;29:479-83.

12. Styrt B. Infection associated with asplenia: risks, mechanisms, and prevention. Am J Med 1990; 88:33N

13. Betrosian AP, Berlet T, Agarwal B. Purpura fulminans in sepsis. Am J Med Sci. 2006; 332: 339-45.

14. Adcock DM, Brozna J, Marla RA. Proposed classification and pathologic mechanisms of purpura fulminans and skin necrosis. Semin Thromb Hemost. 1990;16:333-40.

15. Adcock DM, Hicks MJ. Dermatopathology of skin necrosis associated with purpura fulminans. Semin Thromb Hemost 1990;16:283-92

16. Zeerleder S, Schroeder V, Hack E, et al. TAFI and PAI-1 levels in human sepsis. Thrombosis Res 2006;118:205-12.

17. Rintala E, Kauppila M, Seppala OP, et al. Protein C substitution in sepsis-associated purpura fulminans. Crit Care Med 2000;28:2373-8

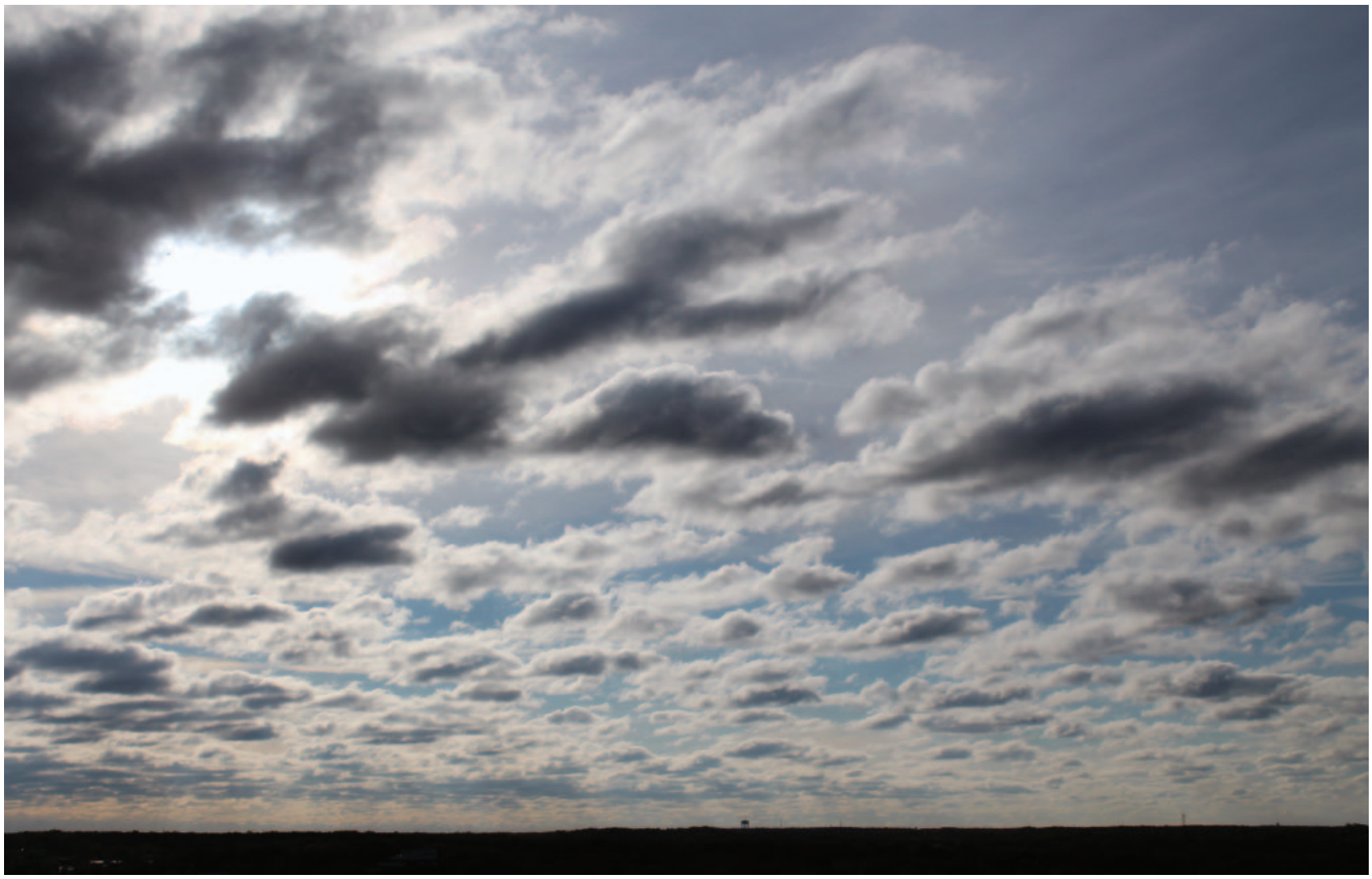

